\title{
Improving the Reliability of Mechanical Components That Have Failed in the Field Due to Repetitive Stress
}

\author{
Seongwoo Woo ${ }^{1, *(1)}$ and Dennis L. O'Neal ${ }^{2}$ \\ 1 Reliability Association of Korea, 146, Sunyoo-ro, Yeongdeungpo-gu, Seoul 07255, Korea \\ 2 Dean of Engineering and Computer Science, Baylor University, Waco, TX 76798-7356, USA; \\ Dennis_ONeal@baylor.edu \\ * Correspondence: twinwoo@yahoo.com; Tel.: +82-10-8602-9084; Fax: +82-2-780-2555
}

Received: 29 November 2018; Accepted: 25 December 2018; Published: 4 January 2019

\begin{abstract}
To improve the reliability of mechanical parts that have failed in the field, a reliability methodology for parametric accelerated life testing (ALT) is proposed. It consists of: (1) a parametric ALT plan, (2) a load analysis, (3) a tailored series of parametric ALTs with action plans, and (4) an evaluation of the final designs to ensure the design requirements are satisfied. This parametric ALT should help an engineer reproduce the fractured or failed parts in a product subjectedto repetitive loading and correct the faulty designs. As a test case, the helix upper dispenser of a refrigerator ice-maker fractured in field was studied. Using a load analysis, we discerned that the helix upper dispenser fracture was due to repetitive loads and a faulty design with a $2 \mathrm{~mm}$ gap between the blade dispenser and the helix upper dispenser. During the first and second ALTs, the fracture in the helix upper dispenser was reproduced. The failure modes and mechanisms found were similar to those of the failed sample in field. As an action plan, the design of the helix upper dispenser was modified by eliminating the $2 \mathrm{~mm}$ gap and adding enforced ribs. In the third ALT there were no problems. After three rounds of parametric ALTs, the reliability of the helix upper dispenser was guaranteed as a 10-year life with an accumulated failure rate of $1 \%$.
\end{abstract}

Keywords: reliability design; helix upper dispenser; fracture; parametric accelerated life testing; faulty designs

\section{Introduction}

A refrigerator is designed to store fresh food. Its evaporator supplies chilled air to both the freezer and refrigerator compartments. A refrigerator that includes an ice-maker can consist of several different subsystems-cabinet, door, shelves and drawers, control system, motor or compressor, heat exchanger, water supply device, and other miscellaneous parts. The total number of components can be as many as 3000. Product reliability is targeted to have at least 10 years of B20 life that will have an accumulated failure rate of $20 \%$ (Figure 1 ).

Because customers have requested the inclusion of an ice-maker in a refrigerator, manufacturers have developed refrigerators with this feature. For this (intended) function, a mechanical module like the ice-maker is designed to harvest ice. As seen in Figure 2, the mechanical parts in an ice-maker should operate under the conditions subjected to it by consumers. In the field, the ice-maker might experience failures which were not anticipated in the design process. In such cases, the company may have to decide to perform a massive recall of the product. Reliability testing should reproduce any defective configurations or uses of the product which failed in field and correct them immediately. However, in this instance, there had been no proper testing methods for the failures of the mechanical product detected in field [1-3]. 


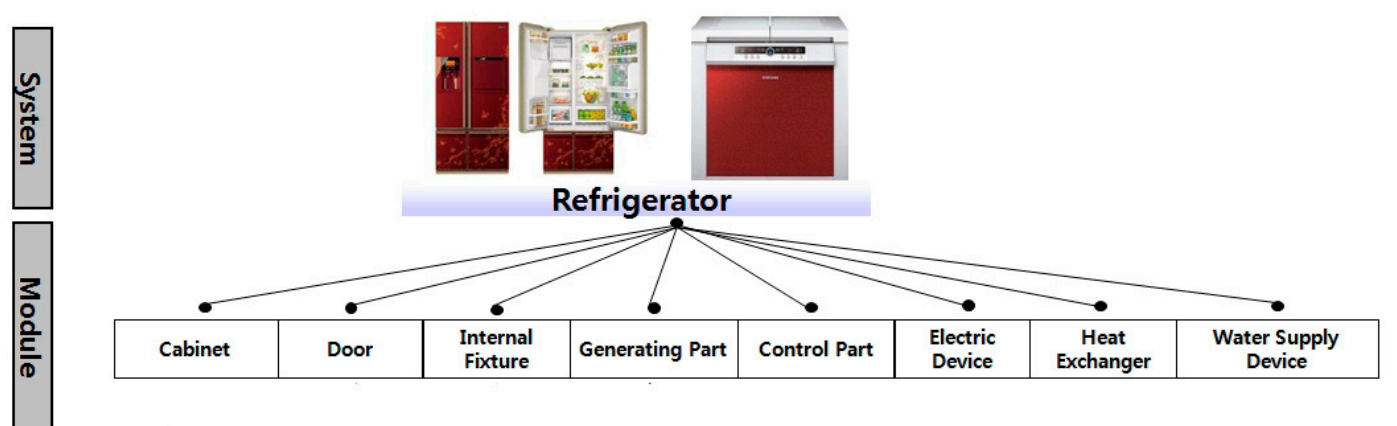

Figure 1. Breakdown of an appliance which includes a refrigeration system, with its modules.

\section{Key Noise Parameter}

N1: Customer Usage \& Load Conditions

N2: Environment Conditions

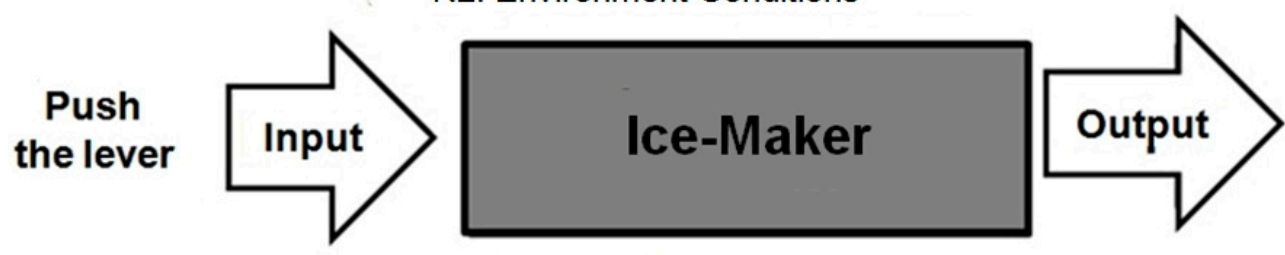

\section{Key Control Parameter}

\section{C1: AC auger motor \\ $\mathrm{C} 2$ : Ice bucket assembly including helix \\ C3: Ice route assembly \\ C4: Lever and controller}

Figure 2. Robust design schematic of a mechanical system, such as an ice-maker.

Repeated loads or overloading due to daily usage may cause structural failure in a product and reduce its lifetime [4,5]. Many engineers think such possibilities can be assessed by: (1) mathematical modeling using Newtonian methods, (2) assessing the time response of the system for dynamic loads, (3) utilizing the rain-flow counting method [6,7], or (4) estimating system damage using the Palmgren-Miner's rule [8]. However, while these analytical methodologies may provide exact answers, there are many assumptions in these methods that simplify the complexities in modeling product failures due to design flaws.

Robust design methods, including the statistical design of experiments (DOE) and the Taguchi approach [9], were developed to carry out optimal design for mechanical products. In particular, Taguchi's robust design method uses parametric design to place it in a position where random "noise" does not affect the outcome. Thus, mechanical systems can be used to find out the proper design parameters and their levels [10-14]. Through utilizing interactions between control factors and noise factors, the parametric design of a mechanical system can be used to determine the proper control factors that make the design robust, regardless of the change of noise factors. In an orthogonal array, as the control factors are assigned to an inner array, the noise factors are assigned to an outer array.

However, because huge experimental computations in the Taguchi product array are required, a lot of design parameters for a mechanical structure need to be considered. As new products are introduced with faulty designs in the mechanical structure, products may be recalled and loss of brand-name value experienced.

The purpose of this paper is to present a reliability methodology of mechanical parts like the fractured helix upper dispenser which is subjected to repetitive loading in field. This reliability methodology includes: (1) a parametric accelerated life testing (ALT) plan, (2) a load analysis, (3) a 
tailored series of parametric ALTs with action plans, and (4) an evaluation to ensure the final design requirements of the mechanical parts were satisfied.

\section{Parametric Accelerated Life Testing}

\subsection{Setting an Overall Parametric ALT Plan}

The reliability of a mechanical system can be defined as the ability of a system or module to function under stated conditions for a specified period of time [15]. It can be illustrated in Figure 3, which includes a component called "the bathtub curve" that consists of three parts [16]. There is initially a decreasing failure rate, then a constant failure rate, and then an increasing failure rate. If a product follows the bathtub curve, it will have difficulty in succeeding in the market. Because of faulty design, the mechanical product will have higher failure rates early in its early and incur financial losses for the company. The company will then need to set goals for new products to (1) reduce early failures, (2) decrease random failures during the product operating time, and (3) increase product lifetime [17]. As the reliability of a mechanical product is improved, the traditional bathtub curve can be transformed into a straight line with the shape parameter $\beta$ (the bottom curve in Figure 3).

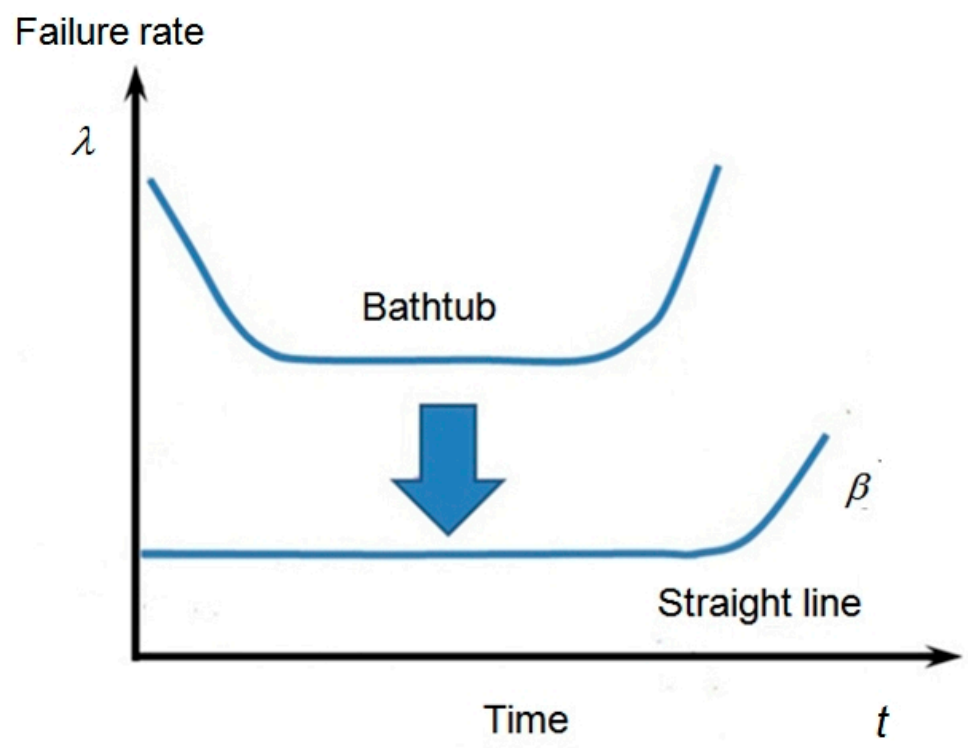

Figure 3. Bathtub curve and straight line with slope $\beta$.

Therefore, the reliability of a mechanical system might be quantified from the product lifetime $L_{B}$ and failure rate $\lambda$ as follows:

$$
R\left(L_{B}\right)=1-F\left(L_{B}\right)=e^{-\lambda L_{B}} \cong 1-\lambda L_{\mathrm{BX}}
$$

This equation is applicable below about 20 percent of the cumulative failures [18]. The reliability design of a mechanical system can be achieved by obtaining the targeted product lifetime $L_{B}$ and failure rate $\lambda$ after reproducing the field failure through parametric ALT and correcting the defective configuration of structures.

In targeting the reliability of a mechanical product in a parametric ALT analysis, there are three cases for modules in a mechanical product: (1) a modified module, (2) a new module, and (3) a similar module to the prior design on the basis of market demand. The ice-maker with a helix upper dispenser discussed here as a case study is a similar module with a faulty design that should be corrected because customers wanted to replace it with a new one. 
The newly designed module $A$ from the field data in Table 1 had a yearly failure rate of $0.35 \%$ per year and a lifetime, $L_{B 1}$, of 2.9 years. To respond to customer claims, a new reliability target for the ice-maker was set as 10 years of B1 life with an accumulative failure rate of one percent.

Table 1. Overall parametric accelerated life testing (ALT) plan of a refrigerator.

\begin{tabular}{|c|c|c|c|c|c|c|c|c|}
\hline \multirow{3}{*}{$\begin{array}{l}\text { Modules } \\
\text { A }\end{array}$} & \multirow{2}{*}{$\begin{array}{l}\text { Market Data } \\
\text { Yearly Failure } \\
\text { Rate, \%/year }\end{array}$} & \multirow{3}{*}{$\begin{array}{l}B_{x} \text { Life, } \\
\text { year } \\
2.9\end{array}$} & \multicolumn{4}{|c|}{ Expected Reliability } & \multicolumn{2}{|c|}{ Targeted Reliability } \\
\hline & & & \multicolumn{3}{|c|}{ Yearly Failure Rate, \%/year } & $\begin{array}{l}B_{x} \text { Life, } \\
\text { year }\end{array}$ & $\begin{array}{l}\text { Yearly Failure } \\
\text { Rate, \%/year }\end{array}$ & $B_{x}$ Life, year \\
\hline & 0.35 & & Similar & $\times 1$ & 0.35 & 2.86 & 0.10 & $10(x=1.0)$ \\
\hline B & 0.24 & 4.2 & New & $\times 5$ & 1.20 & 0.83 & 0.15 & $10(x=1.5)$ \\
\hline $\mathrm{C}$ & 0.30 & 3.3 & Similar & $\times 1$ & 0.30 & 3.33 & 0.10 & $10(x=1.0)$ \\
\hline $\mathrm{D}$ & 0.31 & 3.2 & Modified & $\times 2$ & 0.62 & 1.61 & 0.10 & $10(x=1.0)$ \\
\hline E & 0.15 & 6.7 & Modified & $\times 2$ & 0.30 & 3.33 & 0.15 & $10(x=1.5)$ \\
\hline Others & 0.50 & 2.0 & Similar & $\times 1$ & 0.50 & 2.00 & 0.40 & $10(x=4.0)$ \\
\hline Product & 1.9 & 5.4 & - & - & 3.27 & 3.06 & 1.00 & $10(x=10)$ \\
\hline
\end{tabular}

\subsection{Parametric Accelerated Life Testing of Mechanical Systems}

For solid-state diffusion of impurities in silicon, the junction equation $J$ might be expressed as

$$
J=[a C(x-a)] \cdot \exp \left[-\frac{q}{k T}\left(w-\frac{1}{2} a \xi\right)\right] \cdot v
$$

[Density/Area $] \cdot[\mathrm{Jump}$ Probability $] \cdot[\mathrm{Jump}$ Frequency]

$$
\begin{aligned}
& =-\left[a^{2} v e^{-q w / k T}\right] \cdot \cosh \frac{q a \xi}{2 k T} \frac{\partial C}{\partial x}+\left[2 a v e^{-q w / k T}\right] C \sinh \frac{q a \xi}{2 k T} \\
& =\Phi(x, t, T) \sinh (a \xi) \exp \left(-\frac{Q}{k T}\right) \\
& =A \sinh (a \xi) \exp \left(-\frac{Q}{k T}\right)
\end{aligned}
$$

On the other hand, the reaction process that is dependent on speed might be expressed as

$$
\begin{aligned}
K=K^{+}-K^{-} & =a \frac{k T}{h} e^{-\frac{\Delta E-a S}{k T}}-a \frac{k T}{h} e^{-\frac{\Delta E+a S}{k T}} \\
& =a \frac{k T}{h} e^{-\frac{\Delta E}{k T}} \sinh \left(\frac{a S}{k T}\right)
\end{aligned}
$$

The reaction rate $K$ from Equations (2) and (3) can therefore be summarized as

$$
K=B \sinh (a S) \exp \left(-\frac{E_{a}}{k T}\right)
$$

If the reaction rate in Equation (4) takes an inverse function, the generalized stress model can be obtained as

$$
T F=A[\sinh (a S)]^{-1} \exp \left(\frac{E_{a}}{k T}\right)
$$

The range of the hyperbolic sine stress term $[\sinh (\mathrm{aS})]^{-1}$. in Equation (4) increases the stress as follows: (1) initially $(S)^{-1}$ has a small effect, (2) $(S)^{-n}$ has what is considered a medium effect, and (3) $\left(\mathrm{e}^{\mathrm{aS}}\right)^{-n}$ has a large effect. Accelerated testing is usually conducted in the medium stress range. The hyperbolic sine stress term of Equation (5) in the medium range can be redefined as

$$
T F=A(S)^{-n} \exp \left(\frac{E_{a}}{k T}\right)
$$


The internal (or external) stress in a product is difficult to quantify and use in accelerated testing. Stresses in mechanical systems may come from efforts (or loads) like force, torque, and pressure. For a mechanical system, when replacing stress with effort, the time-to-failure (TF) can be modified as

$$
T F=A(S)^{-n} \exp \left(\frac{E_{a}}{k T}\right)=A(e)^{-\lambda} \exp \left(\frac{E_{a}}{k T}\right)
$$

From the time-to-failure in Equation (7), the acceleration factor can be defined as the ratio between the proper accelerated stress levels and typical operating conditions. The acceleration factor (AF) can be modified to include the effort concepts:

$$
A F=\left(\frac{S_{1}}{S_{0}}\right)^{n}\left[\frac{E_{a}}{k}\left(\frac{1}{T_{0}}-\frac{1}{T_{1}}\right)\right]=\left(\frac{e_{1}}{e_{0}}\right)^{\lambda}\left[\frac{E_{a}}{k}\left(\frac{1}{T_{0}}-\frac{1}{T_{1}}\right)\right]
$$

To carry out parametric ALTs, the sample size equation with the acceleration factors in Equation (8) might be expressed as [19]:

$$
n \geq(r+1) \cdot \frac{1}{x} \cdot\left(\frac{L_{B X}^{*}}{A F \cdot h_{a}}\right)^{\beta}+r
$$

If the reliability of the mechanical system was targeted, the number of required test cycles (or mission cycles) can be obtained for a given sample size. Through parametric ALTs, the faulty designs of a mechanical system can be identified to achieve the desired reliability target [20-22].

The estimated lifetime $L_{B x}$ in each ALT is approximated as

$$
L_{B x}^{\beta} \cong x \cdot \frac{n \cdot\left(h_{a} \cdot A F\right)^{\beta}}{r+1}
$$

Let $x=\lambda \cdot L_{B x}$. The estimated failure rate of the design samples $\lambda$ can be described as

$$
\lambda \cong \frac{1}{L_{B x}} \cdot(r+1) \cdot \frac{L_{B}^{\beta}}{n \cdot\left(h_{a} \cdot A F\right)^{\beta}}
$$

In each ALT, by quantifying the reliability from the multiplication of the estimated $L_{B x}$ life and failure rate $\lambda$, we can ensure the reliability of the final design for a mechanical system.

\subsection{Case Study-Reliability Design of the Helix Upper Dispenser in an Ice-Maker}

Since the customer needs ice, an ice-maker is designed to harvest ice. The primary parts in an ice-maker consist of the bucket case, helix support, helix dispenser clamp, blade dispenser, helix upper dispenser, and blade, as shown in Figure 4.

In the field, these ice-maker parts in a refrigerator cracked and fractured due to design failures under unknown customer usage conditions. Field data indicated that the damaged products may have had two structural design flaws: (1) a $2 \mathrm{~mm}$ gap between the blade dispenser and the helix upper dispenser, and (2) a weld line around the impact area of the helix upper dispenser. Below $-20{ }^{\circ} \mathrm{C}$ the rotating blade dispenser (stainless steel) impacts the fixed helix upper dispenser (plastic) while the crushed ice is being harvested. A crack may occur in the helix dispenser (Figure 5). 


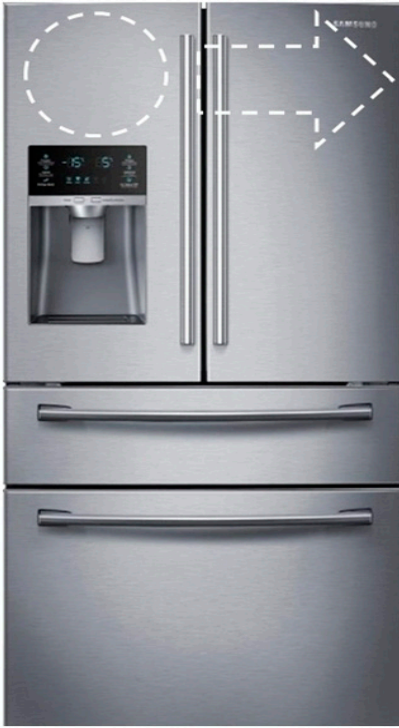

(a)

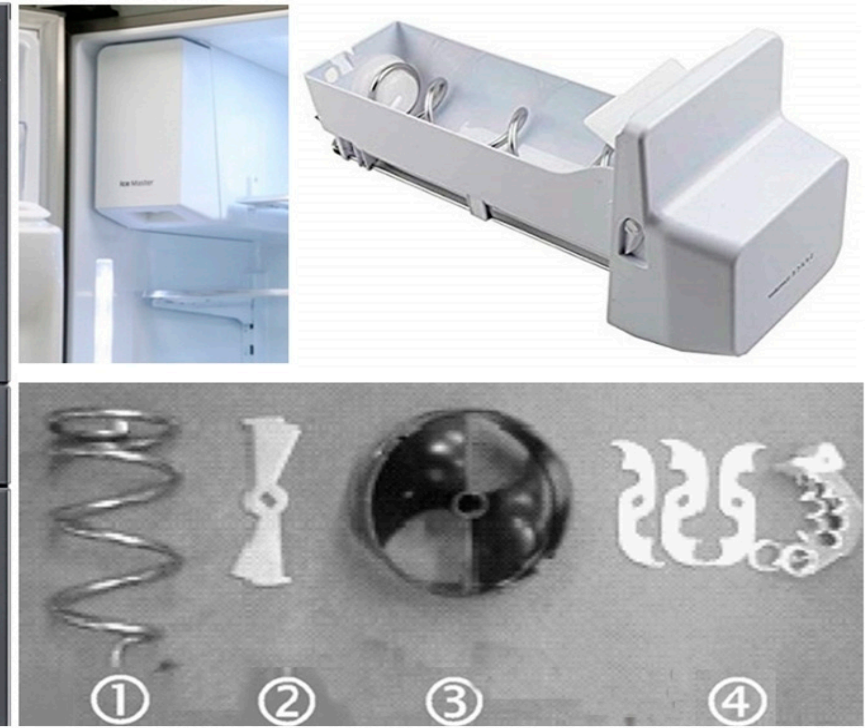

(b)

Figure 4. Refrigerator and ice-maker assembly. (a) Refrigerator; (b) mechanical parts of an ice-maker assembly: helix support (1), blade dispenser (2), helix upper dispenser (3), and blade (4).
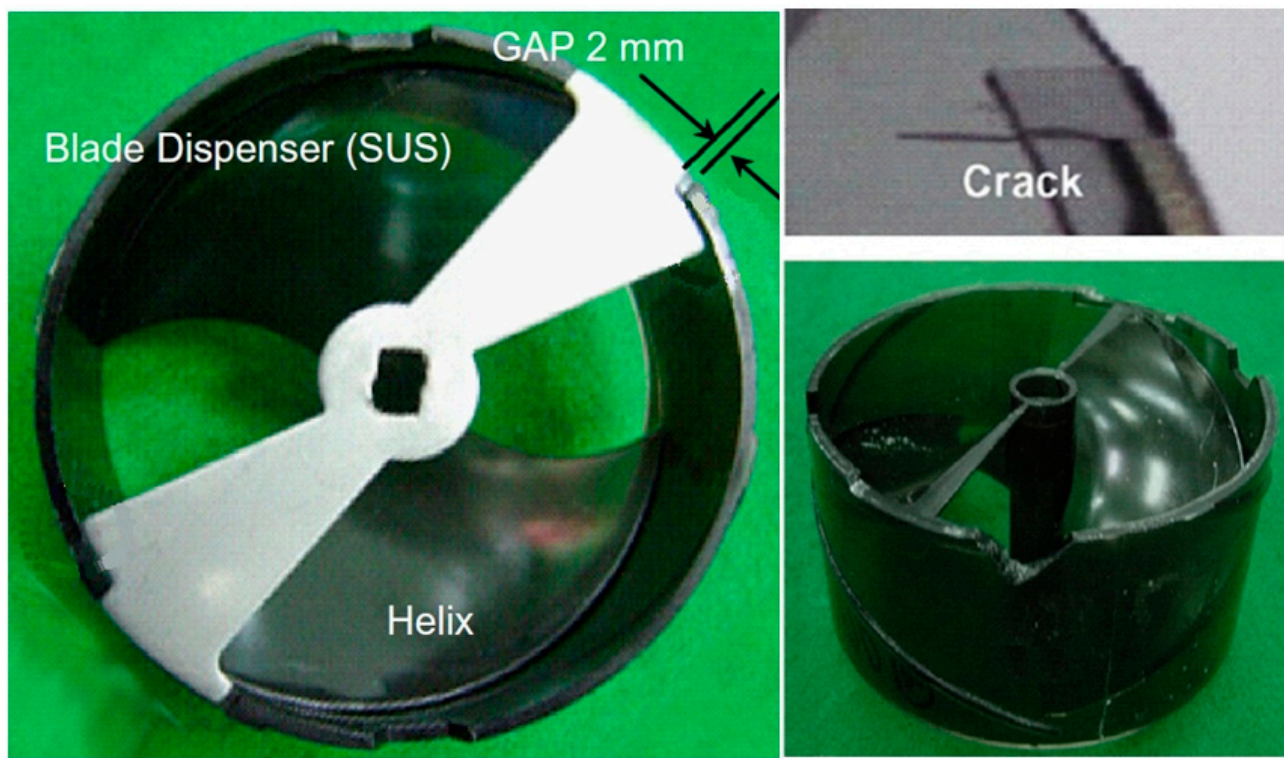

Figure 5. Damaged helix upper dispenser after use.

By utilizing the above failure analysis (and tests), fractures that started in voids inside mechanical parts such as gear have been shown to propagate to their ends [23-30]. In particular, intergranular fractures of austenitic stainless steels have been identified and discussed in a similar way to the failure of the helix dispenser [31]. A phase field visco-plastic model has also been proposed to describe the influence of the loading rate on the ductile fracture [32]. Cracks in the helix dispenser require the manufacturer to redesign the product to keep it functioning for its expected lifetime.

If repetitive loads are applied to the product structure and there are design faults, the structure will fail short of its desired lifetime. Therefore, an ice-maker's actual lifetime depends on faulty parts like the helix upper dispenser. To reproduce and correct the part(s), an engineer is required to conduct reliability testing like parametric ALT for a new design. The process consists of (1) a load analysis for the returned product, (2) the utilization of parametric ALTs with action plans, and (3) the verification of whether the reliability target of final designs has been achieved. 
Ice-making involves several repetitive mechanical processes: (1) filtered water supplies the tray; (2) water freezes into ice via cold air in the heat exchanger; and (3) the ice is harvested until the bucket is full. When the customer pushes the lever by force, cubed or crushed ice is then dispensed. In this ice-making process, the ice-maker parts receive a variety of mechanical loads.

In the United States, refrigerators are designed to produce 10 cubes per use and upto 200 cubes a day. Because the ice-maker system is repetitively used in both cubed and crushed ice modes, it is continuously subjected to mechanical loads. Ice production may also be influenced by customer usage conditions such as water pressure, ice consumption, refrigerator notch settings, and the number of times the door is opened.

Figure 6 provides an overview of the schematic of an ice-maker that represents the mechanical load transfer in the ice bucket assembly using a bond graph model. To generate enough torque to crush the ice, an AC motor provides power through the gear system which is then transferred to the ice bucket assembly. Through the helix blade dispenser and the upper dispenser in the bucket, the ice is distributed by the blade. If subjected to different loads, the ice can also be crushed.

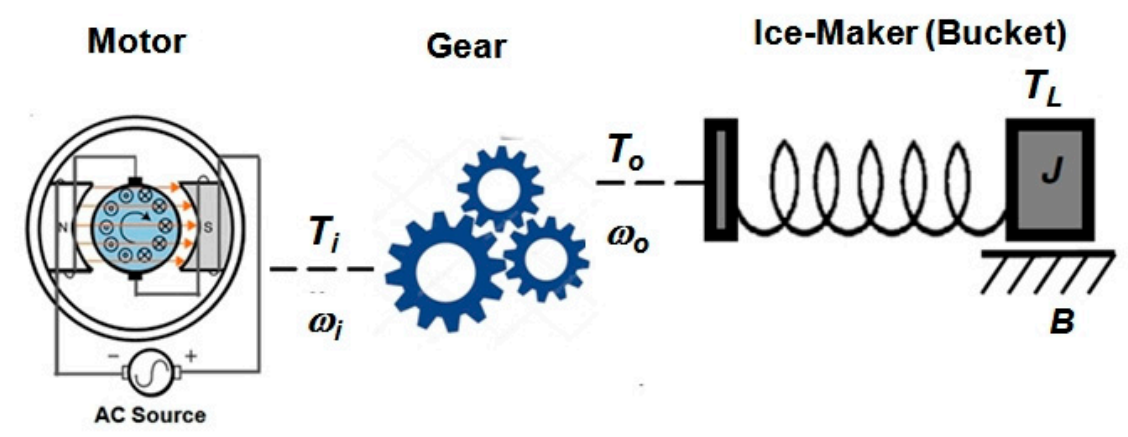

(a)

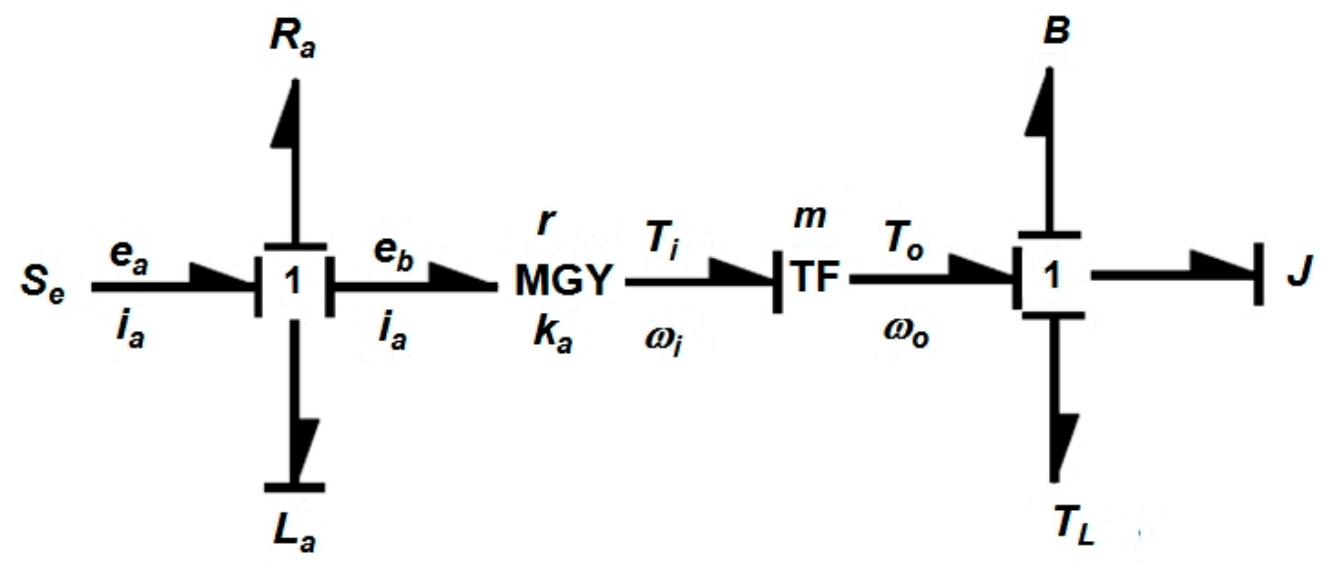

(b)

Figure 6. Design concept of an ice-maker. (a) Schematic diagram of auger motor and ice bucket assembly. (b) Bond graph modeling of auger motor and ice bucket assembly.

To derive the state equations, the bond graph model in Figure $6 \mathrm{~b}$ can be solved at each node, that is,

$$
\begin{gathered}
d f \times E_{2} / d t=1 / L_{a} \times e E_{2} \\
d f M_{2} / d t=1 / J \times e M_{2}
\end{gathered}
$$

The junction from Equation (12) is

$$
e E_{2}=e_{a}-e E_{3}
$$




$$
e E_{3}=R_{a} \times f E_{3}
$$

The junction from Equation (13) is

$$
\begin{gathered}
e M_{2}=e M_{1}-e M_{3} \\
e M_{1}=\left(K_{a} \times i\right)-T_{\text {Pulse }} \\
e M_{3}=B \times f M_{3}
\end{gathered}
$$

Because $f M_{1}=f M_{2}=f M_{3}=\omega$ and $i=f E_{1}=f E_{2}=f E_{3}=i_{a}$ from Equation (14)

$$
\begin{gathered}
e E_{2}=e_{a}-R_{a} \times f E_{3} \\
f E_{2}=f E_{3}=i_{a}
\end{gathered}
$$

If substituting Equations (16) and (17) into Equation (12), then

$$
d i_{a} / d t=1 / L_{a} \times\left(e_{a}-R_{a} \times i_{a}\right)
$$

And from Equations (15) we can obtain

$$
\begin{gathered}
e M_{2}=\left[\left(K_{a} \times i\right)-T_{L}\right]-B \times f M_{3} \\
i=i_{a} \\
f M_{3}=f M_{2}=\omega
\end{gathered}
$$

If substituting Equations (19) into (13), then

$$
d \omega / d t=1 / J \times\left[\left(K_{a} \times i\right)-T_{L}\right]-B \times \omega
$$

We can obtain the state equation from Equations (18) and (20) as follows:

$$
\left[\begin{array}{l}
d i_{a} / d t \\
d \omega / d t
\end{array}\right]=\left[\begin{array}{cc}
-R_{a} / L_{a} & 0 \\
m k_{a} & -B / J
\end{array}\right]\left[\begin{array}{c}
i_{a} \\
\omega
\end{array}\right]+\left[\begin{array}{c}
1 / L_{a} \\
0
\end{array}\right] e_{a}+\left[\begin{array}{c}
1 \\
-1 / J
\end{array}\right] T_{L}
$$

When Equation (21) is integrated, the output of the ac-motor and ice bucket assembly is obtained as

$$
y_{p}=\left[\begin{array}{ll}
0 & 1
\end{array}\right]\left[\begin{array}{l}
i_{a} \\
\omega
\end{array}\right]
$$

From Equation (21) we know that the lifetime of the ice bucket assembly depends on the stress (or torque) due to forces required to crush the ice. The life-stress model (LS model) in Equation (7) can then be modified as

$$
T F=A(S)^{-n}=A T_{L}^{-\lambda}=A\left(F_{c} \times R\right)^{-\lambda}=B\left(F_{c}\right)^{-\lambda}
$$

Therefore, the AF can be derived as

$$
A F=\left(\frac{S_{1}}{S_{0}}\right)^{n}=\left(\frac{T_{1}}{T_{0}}\right)^{\lambda}=\left(\frac{F_{1} \times R}{F_{0} \times R}\right)^{\lambda}=\left(\frac{F_{1}}{F_{0}}\right)^{\lambda}
$$

We can carry out parametric ALT from Equation (9) until the required mission cycles that provide the reliability target of 10 years of B1 life are achieved.

The environment operating conditions of the ice bucket assembly in a refrigerator icemaker can vary from approximately -15 to $-30{ }^{\circ} \mathrm{C}$ with a relative humidity ranging from $0 \%$ to $20 \%$. Depending 
on customer usage, an ice dispenser is used an average of approximately 3-18 times per day. Under maximum use for 10 years, the dispenser incurs about 65,700 usage cycles. Data from the motor company specifies that normal torque is $0.69 \mathrm{kN}-\mathrm{cm}$ and maximum torque is $1.47 \mathrm{kN}-\mathrm{cm}$. Assuming the cumulative damage exponent $\lambda=2$, the acceleration factor is approximately 5 in Equation (24).

For 10 years of B1 life, the test cycles for a sample of ten pieces (calculated using Equation (9)) were approximately 42,000 cycles if the shape parameter was supposed to be 2.0. This parametric ALT is designed to ensure a B1 life of 10 years so that it would fail less than once during 42,000 cycles. Figure 7 shows the experimental setup of an ALT for the reproduction of the failed helix upper dispenser in the field. Figure 8 represents the duty cycles for the ice-crushing load $T_{L}$.

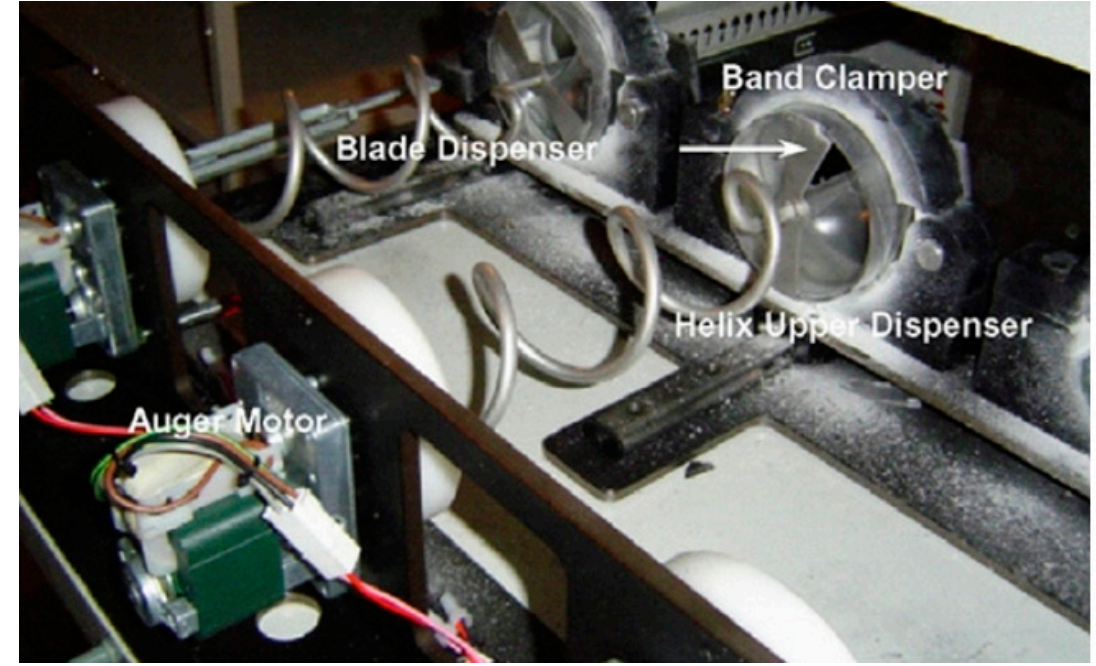

(a)

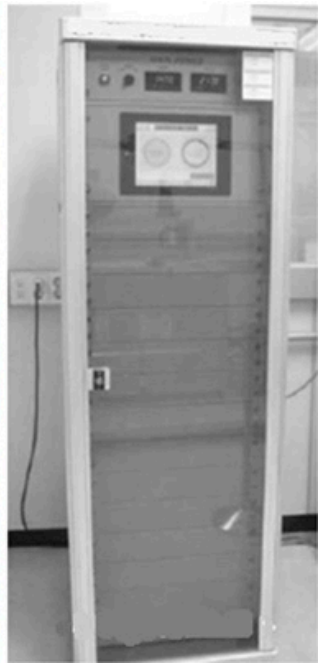

(b)

Figure 7. Equipment used in accelerated life testing and controller. (a) ALT Equipment; (b) controller.

\section{$5 \mathrm{~s}$}

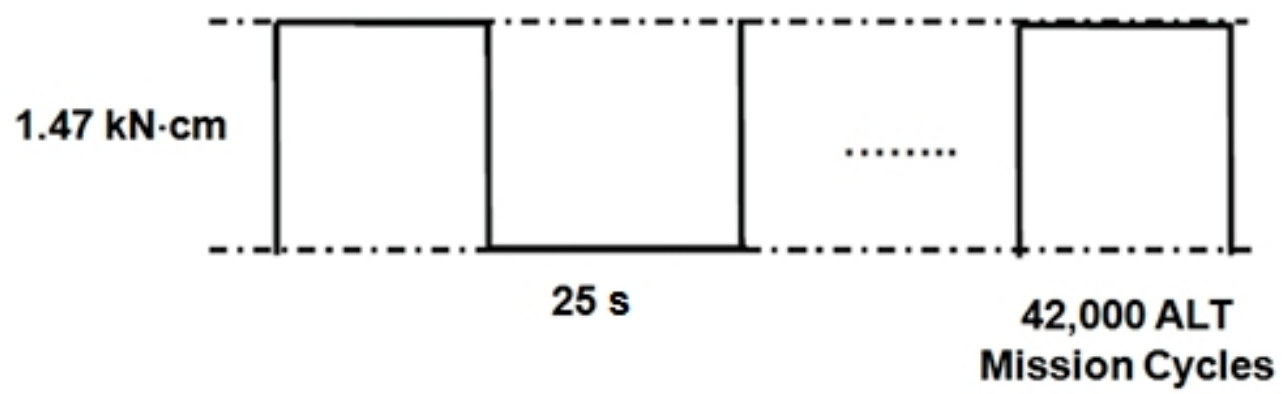

Figure 8. Duty cycles of disturbance load $T_{L}$ on the band clamper.

The equipment in the chamber was designed to operate down to a temperature of about $-30{ }^{\circ} \mathrm{C}$. The controller outside can start or stop the equipment and can indicate the completed test cycles and the test periods, such as sample on/off time. To apply the maximum ice-crushing torque $T_{L}$, the helix upper dispenser and the blade dispenser were bolted together with a band clamper. As the controller gives the start signal, the augermotor rotates. At this point, the rotating blade dispenser impacts the fixed helix upper dispenser to the maximum mechanical ice-crushing torque $(1.47 \mathrm{kN}-\mathrm{cm})$.

\section{Results \& Discussion}

In the first ALT, the helix upper dispenser fractured at 170 cycles, 5200 cycles, 7880 cycles, 8800 cycles, and 11,600 cycles. Figure 9 shows a photograph comparing the failed product from the field and that from the first ALT, respectively. Because they are similar, by parametric ALT we were 
able to reproduce the fractured helix upper dispenser. There was a structural design flaw-a $2 \mathrm{~mm}$ gap between the blade dispenser and the helix upper dispenser. As the blade dispenser (stainless steel) struck the helix upper dispenser (plastic), it cracked and fractured. Figure 10 represents the graphical analysis of the ALT results and field data on a Weibull plot. The shape parameter in the first ALT was estimated to be 2.0. For the final design, the shape parameter from the Weibull plot was confirmed to be 4.78 .

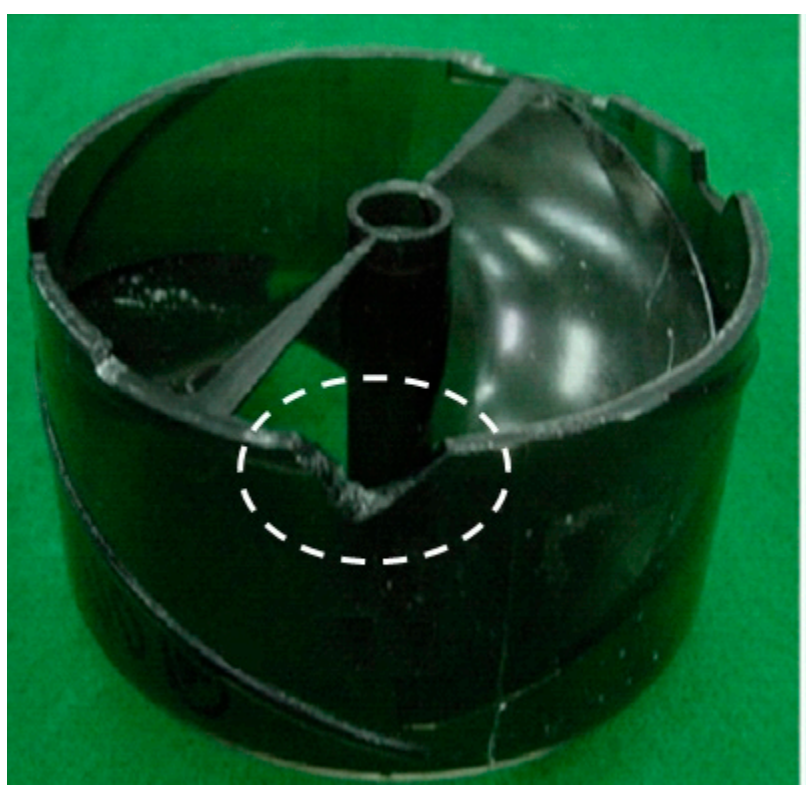

(a)

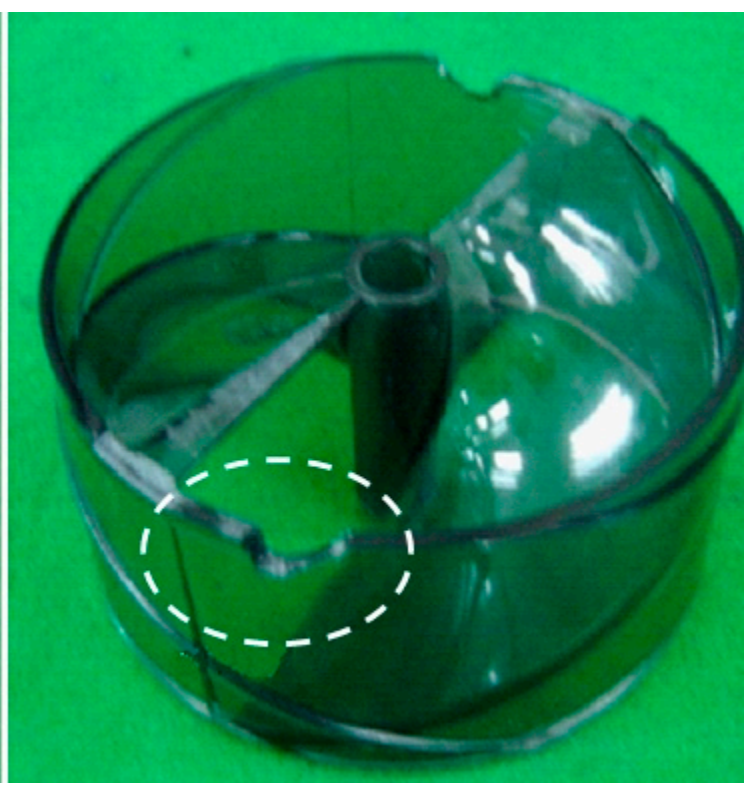

(b)

Figure 9. Failed helix upper dispensers in field and during the first ALT. (a) Failed product in field; (b) Product with crack after first ALT.

\section{Unreliability, F(t)}

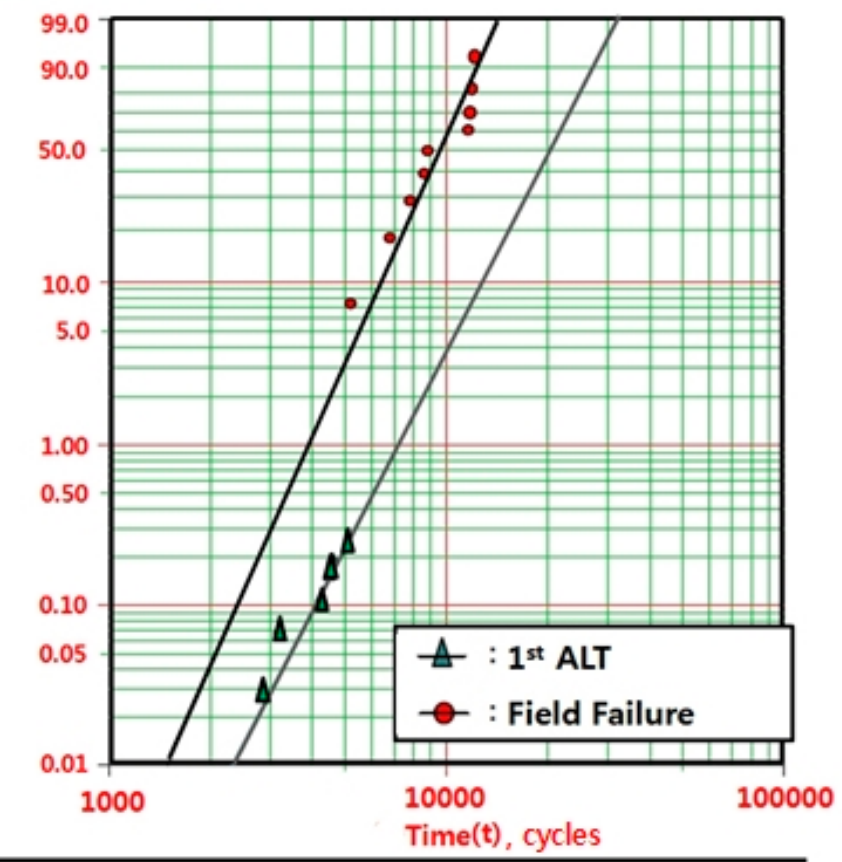

$\beta 1=4.7785, \eta 1=1.026 \times 10^{4}$ $\beta 2=4.0710, \eta 2=2.222 \times 10^{4}$

Figure 10. Field data and results of ALT on Weibull chart. 
To withstand repetitive impact loads, the problematic helix upper dispenser used in field was redesigned as follows: the $2 \mathrm{~mm}$ gap between the blade dispenser and helix upper dispenser was eliminated (Figure 11).

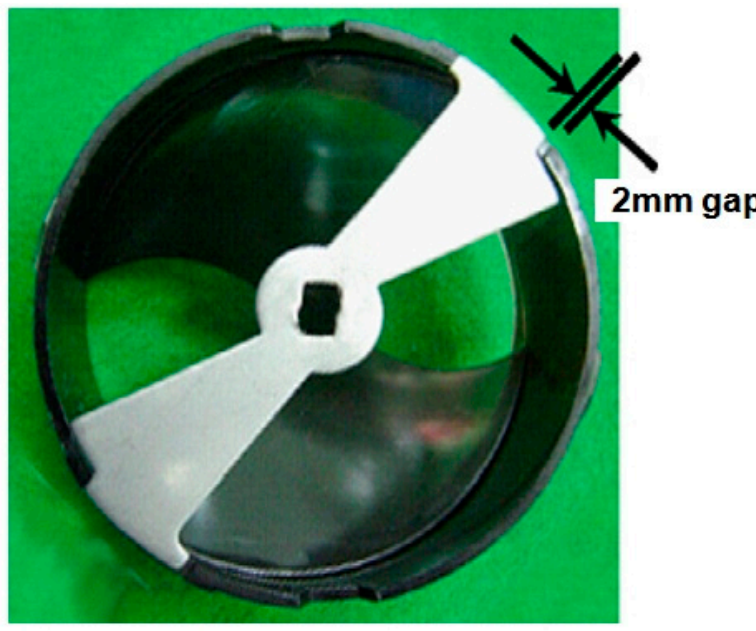

(a)

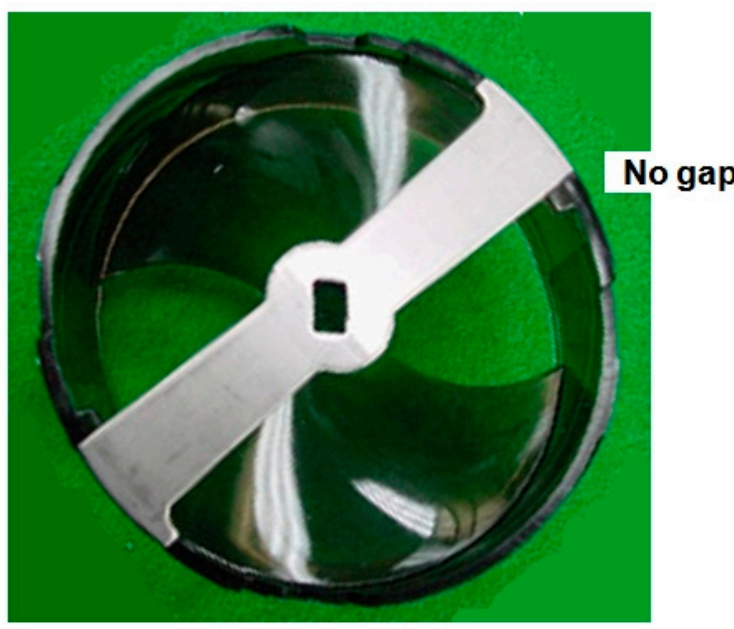

(b)

Figure 11. Redesigned helix upper dispenser. (a) Old design; (b) New design.

In the second ALT, the helix upper dispenser fractured at 17,000 cycles, 25,000 cycles, 28,200 cycles, and 38,000 cycles. When the gap between the blade dispenser and the helix upper dispenser was eliminated, the lifetime of the helix upper dispenser was extended. Because the helix upper dispenser did not have enough strength for stress, 42,000 mission cycles in the second ALT still wasn't met. As an action plan, a reinforced rib on the outside of the helix was added.

In the third ALT, there were no problems until 75,000 cycles. Over the course of three ALTs with these design changes, the helix upper dispenser was guaranteed to have 10 years of B1 life. Table 2 shows a summary of the results of the ALTs.

Table 2. Results of ALTs.

\begin{tabular}{|c|c|c|c|}
\hline \multirow{2}{*}{ Parametric ALT } & 1st ALT & 2nd ALT & 3rd ALT \\
\hline & Initial Design & Second Design & Final Design \\
\hline $\begin{array}{l}\text { Over the course of } 42,000 \\
\text { cycles, the helix upper } \\
\text { dispenser has no } \\
\text { problems }\end{array}$ & $\begin{array}{l}170 \text { cycles: } 1 / 10 \text { fracture } \\
5200 \text { cycles: } 1 / 10 \text { fracture } \\
7880 \text { cycles: } 2 / 10 \text { fracture } \\
8880 \text { cycles: } 2 / 10 \text { fracture } \\
11,600 \text { cycles: } 4 / 10 \text { fracture }\end{array}$ & $\begin{array}{l}17,000 \text { cycles: } 1 / 6 \text { fracture } \\
25,000 \text { cycles: } 3 / 6 \text { fracture } \\
28,000 \text { cycles: } 1 / 6 \text { fracture } \\
38,000 \text { cycles: } 1 / 6 \text { fracture }\end{array}$ & $\begin{array}{l}42,000 \text { cycles: } 6 / 6 \text { OK } \\
75,000 \text { cycles: } 6 / 6 \text { OK }\end{array}$ \\
\hline \multicolumn{4}{|l|}{ Helix structure } \\
\hline $\begin{array}{l}\text { Material and } \\
\text { specification }\end{array}$ & $\mathrm{C} 1:$ Gap of $2 \mathrm{~mm} \rightarrow$ & $\begin{array}{l}\text { C2: Added rib on the outside of } \\
\text { helix }\end{array}$ & - \\
\hline
\end{tabular}

\section{Conclusions}

To improve the reliability of a mechanical part that fails in the field, we have suggested a reliability methodology that includes: (1) a parametric ALT plan, (2) a load analysis, (3) a tailored series of parametric ALTs with action plans, and (4) an evaluation of the final design requirements of the 
mechanical part to ensure the requirements were satisfied. A helix upper dispenser fractured in field was used as a case study.

Regarding the parametric ALTs of the helix upper dispenser, based on the products that failed both in the field and in the first ALT, the helix upper dispenser fractured around a $2 \mathrm{~mm}$ gap between the blade dispenser and helix upper dispenser. When crushed ice was being made, the blade dispenser (stainless steel) struck the plastic helix upper dispenser. The helix upper dispenser, subjected to these repetitive stresses, fractured short of its expected lifetime. As a corrective action plan, the $2 \mathrm{~mm}$ gap was eliminated.

During the second ALT, the helix upper dispenser also fractured because it did not have enough strength to withstand repetitive strikes from the blade dispenser. As a corrective action plan, a reinforced rib on the outside of the helix was added. After a sequence of ALT testing, a helix upper dispenser with the proper values for the design parameters was determined to meet the reliability target of 10 years of a B1 life. These were shown to be effective in reproducing the reliability of the helix upper dispenser claimed in field and in enhancing its reliability. This reliability design methodology should be applicable to other mechanical systems such as automobiles, airplanes, construction equipment, washing machines, vacuum cleaners, and civil structures like bridges.

Author Contributions: The primary author (S.W.) was responsible for the experimental testing. Both authors contributed to the analysis and writing of the paper.

Conflicts of Interest: The authors declare no conflicts of interest.

\section{Abbreviations}

$B$

$B X$

$E_{a}$

$e$

$e_{a}$

$e_{b}$

$e_{f}$

$f$

$F_{c}$

$F(t)$

$h$

$h^{*}$

$i_{a}$

$i_{f}$

$J$

$k$

$k_{a}$

$L_{a}$

$L_{B}$

$m$

MGY

$n$

$r$

$r$

$R_{a}$

$S$

$t_{i}$

$T$

$T_{L}$

viscous friction coefficient

time which isan accumulated failure rate of $X \%$, durability index

activation energy, $\mathrm{eV}$

effort

applied voltage, $\mathrm{V}$

counter-electromotive force

field voltage, $\mathrm{V}$

flow

ice crushing force, $\mathrm{kN}$

unreliability

testing cycles (or cycles)

non-dimensional testing cycles, $h^{*}=h / L_{B} \geq 1$

applied current, $A$

field current, $A$

momentum of inertia, $\mathrm{kg} \mathrm{m}^{2}$

Boltzmann's constant, $8.62 \times 10^{-5} \mathrm{eVdeg}^{-1}$

constant of the counter-electromotive force

electromagnetic inductance

target BX life and $x=0.01 X$, on the condition that $x \leq 0.2$

gear ratio

gyrator in causal forms for basic 2-ports and 3-ports

number of test samples

failed numbers

coefficient of gyrator

electromagnetic resistance

stress

test time for each sample

torque, $\mathrm{kN} \mathrm{cm}$

ice-crushing torque in bucket, $\mathrm{kN} \mathrm{cm}$ 


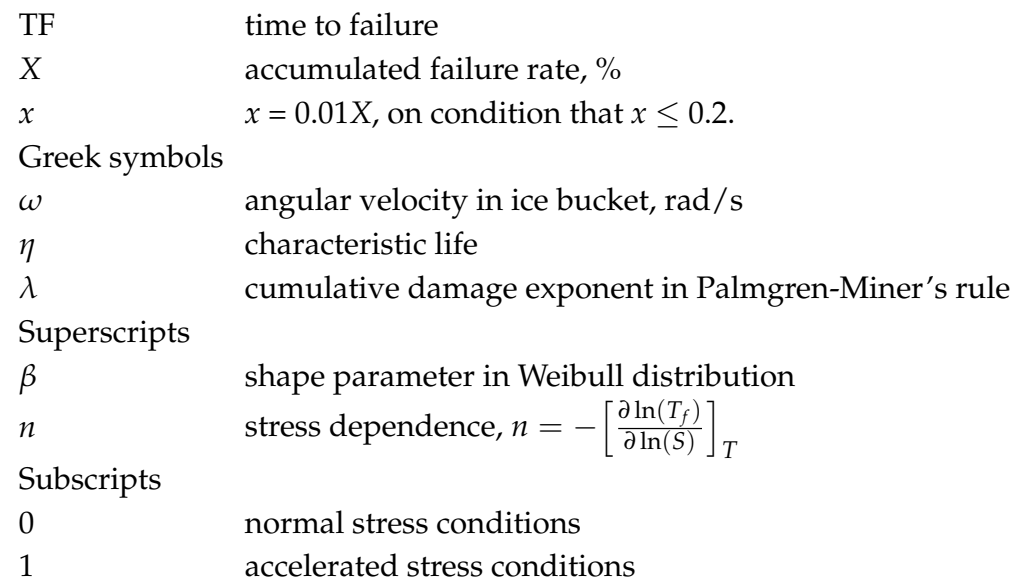

\section{References}

1. Magaziner, I.C.; Patinkin, M. Cold Competition: GE Wages the Refrigerator War. Harv. Bus. Rev. 1989, 89, 114-124.

2. Bertsche, B. Reliability in Automotive and Mechanical Engineering: Determination of Component and System Reliability; Springer: Berlin, Germany, 2010.

3. O'Connor, P.; Kleyner, A. Practical Reliability Engineering, 5th ed.; Wiley \& Sons: Hoboken, NJ, USA, 2012.

4. Toribio, J.; Lorenzo, M.; Vergara, D.; Aguado, L. The Role of Overloading on the Reduction of Residual Stress by Cyclic Loading in Cold-Drawn Prestressing Steel Wires. Appl. Sci. 2017, 7, 84. [CrossRef]

5. Nie, B.; Zhao, Z.; Ouyang, Y.; Chen, D.; Chen, H.; Sun, H.; Liu, S. Effect of Low Cycle Fatigue Pre-damage on Very High Cycle Fatigue Behavior of TC21 Titanium Alloy. Materials 2017, 10, 1384. [CrossRef] [PubMed]

6. Matsuishi, M.; Endo, T. Fatigue of metals subjected to varying stress. Jpn. Soc. Mech. Eng. 1968, 68, 37-40.

7. Mottand Robert, L. Machine Elements in Mechanical Design, 4th ed.; Pearson Prentice Hall: Upper Saddle River, NJ, USA, 2004.

8. Palmgren, A.G. Die Lebensdauer von Kugellagern Zeitschrift des Vereines Deutscher Ingenieure. Sci. Res. 1924, 68, 339-341.

9. Taguchi, G. Off-line and on-line quality control systems. In Proceedings of the International Conference on Quality Control, Tokyo, Japan, October 1978.

10. Taguchi, G.; Shih-Chung, T. Introduction to Quality Engineering: Bringing Quality Engineering Upstream; American Society of Mechanical Engineering: New York, NY, USA, 1992.

11. Ashley, S. Applying Taguchi's quality engineering to technology development. Mech. Eng. 1992, 114, 58.

12. Wilkins, J. Putting Taguchi Methods to Work to Solve Design Flaws. Qual. Prog. 2000, 33, 55-59.

13. Phadke, M. Quality Engineering Using Robust Design; Englewood Cliffs: Prentice Hall, NJ, USA, 1989.

14. Byrne, D.; Taguchi, S. The Taguchi approach to parameter design. Qual. Prog. 1987, 20, 19-26.

15. IEEE Standard Glossary of Software Engineering Terminology, IEEE Std 610.12-1990; Standards Coordinating Committee of the Computer Society of IEEE: New York, NY, USA, 1990.

16. Klutke, G.; Kiessler, P.C.; Wortman, M.A. A critical look at the bathtub curve. IEEE Trans. Reliab. 2015, 52, 125-129. [CrossRef]

17. Duane, J.T. Learning Curve Approach to Reliability Monitoring. IEEE Trans. Aerosp. 1964, 2, 563-566. [CrossRef]

18. Kreyszig, E. Advanced Engineering Mathematics, 9th ed.; John Wiley and Son: Hoboken, NJ, USA, 2006 ; p. 683.

19. Woo, S.; O'Neal, D. Reliability Design of Mechanical Systems Subject to Repetitive Stresses. Recent Patents Mech. Eng. 2015, 8, 222-234. [CrossRef]

20. Woo, S.; O'Neal, D.; Pecht, M. Improving the reliability of a water dispenser lever in a refrigerator subjected to repetitive stresses. Eng. Fail. Anal. 2009, 16, 1597-1606. [CrossRef]

21. Woo, S.; O'Neal, D.; Pecht, M. Design of a Hinge kit system in a Kimchi refrigerator receiving repetitive stresses. Eng. Fail. Anal. 2009, 16, 1655-1665. [CrossRef]

22. Woo, S.; O'Neal, D.; Pecht, M. Failure analysis and redesign of the evaporator tubing in a Kimchi refrigerator. Eng. Fail. Anal. 2010, 17, 369-379. [CrossRef] 
23. Zhao, F.; Ding, X.; Fan, X.; Cui, R.; Li, Y.; Wang, T. Contact Fatigue Failure Analysis of Helical Gears with Non-Entire Tooth Meshing Tests. Metals 2018, 8, 693. [CrossRef]

24. Hamandi, F.; Laughlin, R.; Goswami, T. Failure Analysis of PHILOS Plate Construct Used for Pantalar Arthrodesis Paper II-Screws and FEM Simulations. Metals 2018, 8, 279. [CrossRef]

25. Alqedairi, A.; Alfawaz, H.; Rabba, A.; Almutairi, A.; Alnafaiy, S.; Mohammed, M.K. Failure Analysis and Reliability of Ni-Ti-Based Dental Rotary Files Subjected to Cyclic Fatigue. Metals 2018, 8, 36. [CrossRef]

26. Cao, X.; Xu, L.; Xu, X.; Wang, Q. Fatigue Fracture Characteristics of Ti6Al4V Subjected to Ultrasonic Nanocrystal Surface Modification. Metals 2018, 8, 77. [CrossRef]

27. Nagarajan, V.; Putatunda, S.; Boileau, J. Fatigue Crack Growth Behavior of Austempered AISI 4140 Steel with Dissolved Hydrogen. Metals 2017, 7, 466. [CrossRef]

28. Zhang, W.; Wang, H.; Zhang, J.; Dai, W.; Huang, Y. Brittle Fracture Behaviors of Large Die Holders Used in Hot Die Forging. Metals 2017, 7, 198. [CrossRef]

29. Alvarez, J.; Lacalle, R.; Arroyo, B.; Cicero, S.; Gutiérrez-Solana, F. Failure Analysis of High Strength Galvanized Bolts Used in Steel Towers. Metals 2016, 6, 163. [CrossRef]

30. Persaud-Sharma, D.; Budianaky, N.; McGoron, A. Mechanical Properties and Tensile Failure Analysis of Novel Bio-absorbable Mg-Zn-Cu and Mg-Zn-Se Alloys for Endovascular Applications. Metals 2013, 3, $23-40$. [CrossRef] [PubMed]

31. Hojna, A. Overview of Intergranular Fracture of Neutron Irradiated Austenitic Stainless Steels. Metals 2017, 7, 392. [CrossRef]

32. Badnava, H.; Etamadi, E.; Msekh, M. A Phase Field Model for Rate-Dependent Ductile Fracture. Metals 2017, 7, 180. [CrossRef]

(C) 2019 by the authors. Licensee MDPI, Basel, Switzerland. This article is an open access article distributed under the terms and conditions of the Creative Commons Attribution (CC BY) license (http:/ / creativecommons.org/licenses/by/4.0/). 